\title{
Improving Adherence to Prescribed Antidiabetics and Cardiovascular Medications in Primary Health Care Centers in Nyala City, South Darfur State-Sudan*
}

\author{
Ahmed Dahab Ahmed ${ }^{1,2}$, Asim Ahmed Elnour ${ }^{3,4 \#}$, Mirghani Abd Elrahman Yousif ${ }^{5}$, \\ Farah Hamad Farah ${ }^{6}$, Hasab Alrasoul Akasha Ahmed Osman ${ }^{7}$, Abobakr Abasaeed ${ }^{8,9}$ \\ ${ }^{1}$ Revolving Drug Fund (RDF), Ministry of Health (MOH), Nyala, Sudan; ${ }^{2}$ Department of Pharmaceutics, Faculty of Pharmacy, \\ Gezira University, Medani, Sudan; ${ }^{3}$ Consultant Clinical Pharmacist, Al Ain Hospital, Abu Dhabi Health Services Company (SEHA), \\ Al Ain, UAE; ${ }^{4}$ Department of Pharmacology, College of Medicine and Health Sciences, UAE University, Al Ain, UAE; ${ }^{5}$ College of \\ Pharmacy, Clinical Pharmacy, Taif University, Taif, KSA; ${ }^{6}$ College of Pharmacy and Health Sciences, Ajman University of Sciences \\ and Technology, Ajman, UAE; ${ }^{7}$ The Epidemiological Laboratory (Epi-Lab), Khartoum, Sudan; ${ }^{8}$ Social and Clinical Pharmacy De- \\ partment, Faculty of Pharmacy, Charles University, Hradec Kralove, Czech Republic; ${ }^{9}$ Registration and Drug Control Department, \\ Ministry of Health, Abu Dhabi, UAE. \\ Email: dahabahmed2001@yahoo.com, "assahura1962@yahoo.com,mirghani53@yahoo.com, f.hamad@ajman.ac.ae, \\ hassabo.akasha@gmail.com,dr_abasaeed@yahoo.co.uk
}

Received October $28^{\text {th }}, 2013$; revised November $28^{\text {th }}, 2013$; accepted December $12^{\text {th }}, 2013$

Copyright (C) 2013 Ahmed Dahab Ahmed et al. This is an open access article distributed under the Creative Commons Attribution License, which permits unrestricted use, distribution, and reproduction in any medium, provided the original work is properly cited.

\begin{abstract}
Aims: Prospective pharmacist's interventions aimed to improve patient's knowledge and behaviors to adhere to medications in patients with type 2 diabetes with or without cardiovascular medical conditions in primary health care (PHCs) centers in Nyala city, South Darfur State, Sudan. Methodology and Materials: 300 patients were enrolled for assessing adherence with the Brief Medication Questionnaire (BMQ) in ten PHCs in Nyala city. We assessed patients' responses to BMQ pre- and post-interventions plan by: complex interventions, humanitarianism and disease outcomes determined by health-related outcomes (SF-36), glycosylated hemoglobin (HbA1c) and blood pressure. Results: BMQ scores have improved significantly in four screens (pre- and post-interventions): regimen [ $4.6 \pm 0.2$ to $1.8 \pm 0.1 ; P=0.001]$, belief $[1.6 \pm 0.3$ to $0.3 \pm 0.3 ; P=0.007]$, recall $[1.7 \pm 0.2$ to $0.6 \pm 0.2 ; P=0.043]$ and access screens $[1.8 \pm 0.1$ to $0.4 \pm 0.1 ; P$ $=0.005]$; which have indicated an improved patients' adherence to medications. Percentage of subjects reaching target of post prandial blood glucose (PPBG) have increased from $28.0 \%$ to $49.3 \%$; $[P=0.02]$ post interventions. PPBG mean values have decreased significantly from $[11.1 \pm 0.6 \mathrm{mmol} / \mathrm{L}$ to $8.1 \pm 0.8 \mathrm{mmol} / \mathrm{L} ; P=0.001]$. Percentage of subjects with improved blood pressure control have increased significantly from [50.3\% to $89.0 \% ; P=0.001]$. Significant differences existed between baseline and post-baseline scores on four of eight SF-36 sub-domains. Conclusions: Pharmacist provided patient education and behavioral interventions were effective in increasing medications knowledge and raising adherence issues in patients with type 2 diabetes with or without cardiovascular chronic medical conditions.
\end{abstract}

Keywords: Adherence; Darfur; Medications; Nyala; PHCs; Sudan

\section{Introduction}

According to a medical literature review published recently in the Annals of Internal Medicine, approximately 50 percent of medications for chronic disease are not taken as prescribed. Failure to take prescribed medications was estimated to cause 10 percent of hospitaliza-

\footnotetext{
*No conflict of interest.
}

"Corresponding author. tions and 125,000 deaths annually. The total cost to the US health system from poor medication adherence was put at $\$ 100$ billion to $\$ 289$ billion per year. Several studies have shown a low adherence rate [1]. In Saudi Arabia and Egypt, for example, adherence rates of only $34.2 \%$ and $15.9 \%$ have been reported, respectively; [2]. A systematic review indicates that adherence to cardiovascular medications in resource-limited countries is sub-optimal and appears very similar to that observed in resource-rich 
countries. Efforts to improve adherence in resource-limited settings should be a priority given the burden of heart disease in this context, the central role of medications in their management, and the clinical and economic consequences of non-adherence [3]. In China, gender difference had been observed for the adherence of antihypertensive medications [4].

The scope of problems due to medications non-adherence is enormously rising. In Sudan, there were very rare scientific articles published about medications adherence. The current needs for medications adherence provide good opportunity to implement an interventional adherence programs in health setup in Sudan. In early 2000, El Zubair and co-workers conducted cross-sectional study of hypertensive patients in Sudan and estimated drug adherence. Factors associated with adherence, status of BP control and occurrence of complications were assessed. Adherence was $59.6 \%$ as measured with the pill count method. They found $92.0 \%$ of compliant patients had controlled BP in comparison with $18.0 \%$ of non-compliant patients, and $30.1 \%$ of the compliant patients had complications in comparison with $46.3 \%$ of the non-compliant patients. While the adherence rate was reasonable, $36.8 \%$ of patients were non-compliant because they could not afford to buy antihypertensive drugs. These patients experienced uncontrolled BP and other complications [5]. We aimed to design approaches (behavioral and educational) that improve patient's knowledge and behaviors as to adhere to antidiabetics and cardiovascular medications. We have imposed continuous structured program for improving adherence to medications and implemented sequentially as a policy in ten primary health care centers (PHC's) in Nyala, South Darfur State, Sudan. The main objective was to promote awareness and explore reasons for non-adherence to antidiabetics and cardiovascular medications. We emphasized pharmacist's role in improving patient's adherence to antidiabetics and cardiovascular medications.

\section{Methodology}

Study design: A multi-centre prospective intervention (pre and post) clinical trial. It was ethically approved by the Ethics Committee in Faculty of Pharmacy at Gezira University, Ministry of health (MOH) in South Darfur State and director of primary health care clinics (PHC's).

Setting: It was performed in 10 PHC's in Nyala city which is located in the western provinces of Sudan, South Darfur State, Sudan.

Patient enrollment: The eligible randomly selected population was composed of all patients with diabetes type 2 with or without cardiovascular diseases visiting the PHC's in Nyala city. The estimated sample size followed the procedure outlined in similar setting [6].
Outcome measures: The study primary outcome measures were improvements in SF-36, $\mathrm{HbA}_{1 \mathrm{c}}$ and blood pressure. The secondary outcomes were improvement to responses to the BMQ (at baseline, at 3 and 6 months post interventions plan).

\subsection{Tools Used to Measure Outcome}

The interventions plan was in the form of: behavioral interventions involved the use of tools to change patient's skill, dosage schedule changes, written refill, pill count, communications with healthcare providers and counseling. Educational interventions involved teaching the patients about the medications and diseases through written communications (handouts, brochures, booklets and posters), public campaigns and direct consultations in the clinics by using face-to-face education sessions.

\subsection{Brief Medication Questionnaire (BMQ) and SF-36}

The validated BMQ is more sensitive in identifying and diagnosing adherence problems [7]. It consists of four sub-scales (regimen, beliefs, recalls and access screens). The tool includes 5-items regimen screen that asks patients how they took each medication in the past week, a 2 -items belief screen that asks about drug effects and bothersome features, and a 2-items recall screen about potential difficulties remembering. While 2-item, access screen evaluates the patient difficulty in buying and refilling their medications in time. The higher the score (positive screen) in each aspect indicates an increased potential for adherence problems (or barrier to adherence). Whereas a negative screen indicates that there was decreased non-adherence or non-barrier to adherence. We used SF-36 to determine improvements in healthrelated quality of life-HRQoL [8].

\section{Results}

A total of 350 eligible patients with diabetes with or without cardiovascular diseases were enrolled, of which 300 patients $85.7 \%$ have successfully completed the study. Thirty patients $8.6 \%$ were considered drop outs because of the irregular follow up and twenty patients $5.7 \%$ were not reachable. Our results indicated a high participants' response rate of $85.0 \%$ and a high number of illiterate $19.7 \%$ and unemployed subjects $31.0 \%$. More than two third of patients were either overweight or obese $67.0 \%$. The number of patients with diabetes and coexisting cardiovascular diseases was high $46.0 \%$, while the number of patients with coexisting diabetes and hypertensions exceeds $24.7 \%$. The socio-demographic characteristics were shown in Table 1. 
Improving Adherence to Prescribed Antidiabetics and Cardiovascular Medications in

Primary Health Care Centers in Nyala City, South Darfur State-Sudan

Table 1. Socio-demographic characteristics of enrolled population $(\mathrm{N}=300)$.

\begin{tabular}{|c|c|c|}
\hline Parameter & Frequency (N) & Percentage (\%) \\
\hline \multicolumn{3}{|c|}{ Age (mean age $\pm \mathrm{SD}, 49.7 \pm 1.2$ years) } \\
\hline 18 to 44 & 75 & 25.0 \\
\hline 45 to 60 & 197 & $65.7^{*}$ \\
\hline$>60$ & 28 & 9.3 \\
\hline \multicolumn{3}{|c|}{ Gender } \\
\hline Male (Mean age \pm SD $50.8 \pm 4.5$ years) & 148 & 49.3 \\
\hline Female (Mean age \pm SD $49.6 \pm 4.4$ years) & 152 & $50.7^{*}$ \\
\hline \multicolumn{3}{|c|}{ Marital status } \\
\hline Married & 276 & $92.0^{*}$ \\
\hline Unmarried & 24 & 8.0 \\
\hline \multicolumn{3}{|c|}{ Educational level } \\
\hline Illiterate & 59 & 19.7 \\
\hline Preliminaryschool & 91 & $30.3^{*}$ \\
\hline Secondary school & 85 & 28.3 \\
\hline University graduate & 63 & 21.0 \\
\hline Post university degrees & 2 & 0.7 \\
\hline \multicolumn{3}{|c|}{ Occupation/work status } \\
\hline Government employee & 111 & $37.0^{*}$ \\
\hline Private employee & 26 & 8.7 \\
\hline Skilled labor & 47 & 15.7 \\
\hline Business & 17 & 5.6 \\
\hline Unemployed & 93 & 31.0 \\
\hline Retired & 6 & 2.0 \\
\hline \multicolumn{3}{|l|}{ Chronic medical condition } \\
\hline Diabetes & 162 & $54.0^{*}$ \\
\hline Diabetes and hypertension & 74 & 24.7 \\
\hline Diabetes and cardiovascular diseases & 64 & 21.3 \\
\hline \multicolumn{3}{|c|}{ Income per month (Sudanese Ginaih/Pound) } \\
\hline $1-499(\leq 6000$ per year $)$ & 116 & 38.7 \\
\hline $500-1000(\geq 6000$ and $<12,000$ per year $)$ & 152 & $50.7^{*}$ \\
\hline$>1000(>12,000$ per year $)$ & 32 & 10.6 \\
\hline \multicolumn{3}{|c|}{ Body max index $\left(\mathrm{Kg} / \mathrm{m}^{2}\right)$} \\
\hline Under weight $<22$ & 1 & 0.3 \\
\hline Normal weight $\leq 25$ & 98 & 32.7 \\
\hline Over weight $>25$ to $<30$ & 186 & $62.0^{*}$ \\
\hline Obesity $>30$ & 15 & 5.0 \\
\hline Total (at each sub row) & 300 & (100) \\
\hline
\end{tabular}

Key: $\mathrm{N}=$ Frequency; $(\%)=$ Percentage; ${ }^{*}$ The highest percentage achieved in raw. 


\subsection{Brief Medication Questionnaire (BMQ) Adherence Measure}

At baseline assessment, nearly half of participants 147 , $49.7 \%$ were able to name their medications. However, at $3^{\text {rd }}$ assessment more than two thirds $241,80.3 \% ; P=$ 0.002 have reported that they knew their medications names. The number of patients who reported that they did not missed their medication was increased from 71, $23.7 \%$ to $184,61.3 \%$ and to $236,78.7 \% ; P=0.001$ at stages 1,2 and 3 ; respectively. More than $90.0 \%$ of respondents have stated that they were aware about their chronic medical conditions; $P=0.459$. At baseline 163 , $54.3 \% ; P=0.001$ of patients had a concern or doubt when asked how well the medications worked for them. The number of patients who said that their medication bother them, was $48,16.0 \% ; 25,8.3 \%$ and $8,2.6 \% ; P=$ 0.015 at stages 1,2 and 3 ; respectively. There were 81 , $27.0 \% ; 55,18.3 \%$ and $33,11.0 \% ; P=0.03$ who admitted that their medications caused side effects (barrier to adherence). $105,35.0 \% ; 75,25.0 \%$ and $55,18.3 \% ; P=$ 0.02 have agreed that it was at least somewhat hard to remember all the doses at assessment 1,2 and 3; respectively. Results revealed $125,41.7 \% ; 99,33.0 \%$ and 65 , $21.6 \% ; P=0.04$ have indicated that it was at least somewhat hard to pay for their medications at assessment 1,2 and 3; respectively. There were $106,35.3 \%$; $72,24.0 \%$ and $36,12.0 \%$ at stages 1,2 and 3, respectively; have said that it was at least somewhat hard to get their refill in time, this barrier to adherence was decreasing significantly; $P=0.042$. Also $120,40.0 \% ; 143,47.6 \%$ and 136 , $45.3 \%$ at stages 1,2 and 3, respectively; have reported that it was at least somewhat hard to read the print on the container; $P=0.285 .226,75.3 \%$ at baseline, $241,80.4 \%$ at $2^{\text {nd }}$ and $280,93.3 \%$ at $3^{\text {rd }}$ assessment, have stated that their dosage times were convenient; $P=0.006$. There were $41,13.6 \% ; 21,7.0 \%$ and $3,1.0 \%$ have stopped taking some of their medications in the past six months during the assessment stages 1,2 and 3, respectively; $P=$ 0.01 . Furthermore, $\mathrm{n}=226,75.3 \% ; 177,59.5 \%$, and 105 , $35.0 \%$, responded that, they did not know how well did their medications worked for them; $P=0.01$.

\subsection{BMQ Adherence Measure by Scoring Procedure}

The responses to each screen were detailed in Table 2 . To determine correlations between screen and demographic parameters, person correlation coefficient was used at 6 months post interventions, Table 3 . The percentage of patients achieved controlled PPBG were $28.0 \%, 37.0 \%$ and $49.3 \%$, moderately controlled $21.0 \%$,

Table 2. Comparison of the BMQ mean scores of the four screens at different assessments intervals.

\begin{tabular}{cccccc}
\hline BMQ Screen scores (Mean $\pm \mathrm{SD})(\mathrm{N}=300)$ & Assessment 1 & Assessment 2 & Assessment 3 & P value \\
\hline Regimen Screen & $4.6 \pm 0.2$ & $2.9 \pm 0.1$ & $1.8 \pm 0.1$ & $0.001^{*}$ \\
Belief Screen & $1.6 \pm 03$ & $0.9 \pm 0.2$ & $0.3 \pm 0.3$ & $0.007^{*}$ \\
Recall Screen & $1.7 \pm 0.2$ & $1.1 \pm 0.3$ & $0.6 \pm 0.2$ & $0.043^{*}$ \\
Access Screen & $1.8 \pm 0.1$ & $1.0 \pm 0.2$ & $0.4 \pm 0.1$ & $0.005^{*}$ \\
\hline
\end{tabular}

Key: ${ }^{*} P<0.05$.

Table 3. Correlation between the BMQ screen and demographic parameters at final stage $(\mathbf{N}=\mathbf{3 0 0})$.

\begin{tabular}{|c|c|c|c|c|c|c|}
\hline \multicolumn{2}{|c|}{ Patient socio-demographic parameter (final assessment, stage 3) } & \multirow{2}{*}{$\begin{array}{c}\text { Regimen } \\
-0.54\end{array}$} & \multirow{2}{*}{$\begin{array}{l}\text { Belief } \\
-0.11\end{array}$} & \multirow{2}{*}{$\begin{array}{c}\text { Recall } \\
-0.06\end{array}$} & \multirow{2}{*}{$\begin{array}{c}\text { Access } \\
-0.16\end{array}$} & \multirow{2}{*}{$\begin{array}{c}\text { Total } \\
-0.4\end{array}$} \\
\hline & Correlation coefficient & & & & & \\
\hline Education & $P$ value & $0.001^{*}$ & $0.049^{*}$ & 0.329 & $0.004^{*}$ & $0.001 *$ \\
\hline \multirow{2}{*}{ Occupation } & Correlation coefficient & 0.38 & 0.16 & 0.08 & 0.14 & 0.32 \\
\hline & $P$ value & $0.001^{*}$ & $0.007^{*}$ & 0.154 & $0.017^{*}$ & $0.001 *$ \\
\hline \multirow{2}{*}{ Body max index } & Correlation coefficient & -0.05 & 0.05 & 0.13 & 0.11 & 0.08 \\
\hline & $P$ value & 0.371 & 0.396 & $0.026^{*}$ & 0.062 & 0.145 \\
\hline \multirow{2}{*}{ Income } & Correlation coefficient & -0.32 & -0.14 & 0.00 & -0.03 & -0.2 \\
\hline & $P$ value & $0.001^{*}$ & $0.014^{*}$ & 0.961 & 0.64 & $0.001 *$ \\
\hline \multirow{2}{*}{ Age } & Correlation coefficient & 0.13 & 0.04 & 0.05 & 0.06 & 0.12 \\
\hline & $P$ value & $0.029^{*}$ & 0.521 & 0.391 & 0.267 & 0.036 \\
\hline \multicolumn{2}{|c|}{ Total number of study patients (at each sub row) } & 300 & 300 & 300 & 300 & 300 \\
\hline
\end{tabular}

Key: ${ }^{*} P<0.05$. 
$27.0 \%$ and $31.0 \%$, poorly controlled $18.0 \%, 15.0 \%$ and $12.0 \%$ and uncontrolled $33.0 \%, 21.0 \%$ and $7.7 \%$ at stages 1, 2 and 3; respectively. A significant decrease in patients PPBG mean values was observed from baseline, at 3 and 6 months $11.1 \pm 0.6 \mathrm{mmol} / \mathrm{L} ; 9.4 \pm 0.5 \mathrm{mmol} / \mathrm{L}$ and $8.1 \pm 0.8 \mathrm{mmol} / \mathrm{L} ; P=0.001$; respectively. The percentage of patients who reached target PPBG levels (controlled) increased from $28.0 \%$ at baseline to $49.3 \%$ at 6 months post interventions. At baseline, $\mathrm{HbA}_{1 \mathrm{c}}$ mean was $10.5 \pm 1.2$ and patients adhered to medications has a mean $\mathrm{HbA}_{1 \mathrm{c}}$ of $7.6 \pm 0.2$. At baseline, BP levels were SBP 135.7 and DBP $81.8 \mathrm{mmHg}$, improved to SBP 123.3 and DBP $77.6 \mathrm{mmHg}$ ] after 6 months, $P=0.001$. The percentage of patients with improved BP controlled levels was $50.3 \%$ vs. $89.0 \% ; P=0.001$ at baseline and post baseline; respectively. While the percentage of patients with improved BP adequate levels decreased $22.7 \%$ vs. $4.7 \% ; P=0.01$, inadequate $18.3 \%$ vs. $4.7 \% ; P=0.03$, with markedly poor $8.7 \%$ vs. $1.7 \% ; P=0.04$ at baseline and 6 months post baseline; respectively. Analysis revealed that significant differences existed between baseline and post baseline scores on SF-36 domains; Table 4.

\section{Discussions}

The main study findings were significant improved BMQ scores in four screens (pre and post interventions): Regimen, Belief, Recall and Access screens; which have indicated an improved patients' adherence to medications. The percentages of subjects reached target post prandial blood glucose (PPBG) have increased post interventions. PPBG mean values have decreased significantly. The percentages of subjects with improved blood pressure control have increased significantly. Remarkable differences existed between baseline and post baseline scores on four of eight SF-36 sub domains.

\subsection{The Participant's Responses to BMQ Adherence Measure}

The percentage of patients who knew their prescribed medications names have increased from 50.0\% at baseline to more than $80.0 \%$ post interventions. There was increase in the number of patients who have reported that they did not miss their medications. Almost all participants indicated that they have previous idea about their disease. Although not tested, but it was anticipated that knowledge test may reveal the precise idea about their knowledge. This finding had been reported in a previous study [9].

The pharmacist's interventions has led to decline in the number of patients who have had a concern or doubt about how well their medications worked for them. The percentage of patients who reported that their prescribed medications worked very well, have improved at 6 months post interventions. This finding strongly supports the sprouting role of pharmacist in patient's medications education. These findings were in line with previous recent study [10] and earlier study [11]. The improved adherence to medications was evident in the decrease in percentage of patients experiencing medications bothersome. More prominent achievement was gained in the declined percentage of patients for those who admitted that their medications caused side effects. The patients expressed their concerns about the cost of medications. However, simplifying the regimen with combinations therapy was offered as a solution to the increased cost. The percentage of patients who have stopped taking their medications in the past six months have reduced from baseline, to $2^{\text {nd }}$ assessment and to final assessment. The percentage of patients who have missed to take their medications decreased at 6 months post interventions. These findings were attributed to continued education,

Table 4. Descriptive statistics and comparison of SF36 mean scores \pm SD $(N=300)$.

\begin{tabular}{lcccc}
\hline SF36 sub domain scale $($ Mean \pm SD) & Stage 1 & Stage 2 & Stage 3 & P value \\
\hline Physical functioning & $65.5 \pm 25.4$ & $69.0 \pm 25.8$ & $74.3 \pm 19.9$ & $0.001^{*}$ \\
Role limitations due to physical health & $53.8 \pm 36.0$ & $47.9 \pm 41.5$ & $48.7 \pm 42.0$ & 0.142 \\
Role limitations due to emotional problems & $56.1 \pm 38.8$ & $66.7 \pm 41.3$ & $58.2 \pm 42.6$ & $0.004^{*}$ \\
Energy/fatigue & $59.8 \pm 22.4$ & $59.8 \pm 24.1$ & $66.1 \pm 20.4$ & $0.001^{*}$ \\
Emotional well-being & $68.9 \pm 23.0$ & $82.7 \pm 20.6$ & $86.8 \pm 14.1$ & $0.001^{*}$ \\
Social functioning & $58.1 \pm 24.7$ & $60.6 \pm 25.6$ & $60.5 \pm 24.4$ & 0.387 \\
Pain & $61.1 \pm 25.0$ & $62.5 \pm 26.8$ & $62.0 \pm 22.8$ & 0.770 \\
General health & $51.3 \pm 10.4$ & $49.9 \pm 10.2$ & $50.3 \pm 10.7$ & 0.252 \\
\hline
\end{tabular}

Key: ${ }^{*} P<0.05$. 
improved skills, available information and discussions with patients as they were involved to ask and talk freely.

\subsection{BMQ Adherence Measure by Scoring Procedure}

Post pharmacist's interventions, there was a significant $P$ $<0.05$, improvement in scores in all BMQ four screens [regimen, belief, access and recall screens] from baseline throughout the assessment intervals which have indicated an improved patients' medications adherence. This was a positive finding and supports the fact entailing the importance of pharmacist in patient education tailored to medications adherence. In this respect the study supports the findings drawn in a similar study using the same BMQ instrument [9]. Patients have received a multiple dose regimen ( 2 or more times/day) and have reported difficulty remembering their medications at the start of the study, which entails the presence of recall barriers. The pharmacist interventions in this respect regarding simplification of regimen, use of combinations and prioritize dispensing chronic medications to patients on chronic diseases as our population facilitated this barrier with resultant improved adherence to medications.

\subsection{Barriers to Medication Adherence}

The results indicated the presence of side effects to medications among few participants. However, the reported problems in medications decreased significantly post pharmacist's interventions. This finding was in line with many other studies [12-14]. Another barrier to medications adherence was that some patients reported not remembering all the doses of their medications which was consistent with previous study [15]. The issue of medications cost was another barrier to adherence to medications and was increasing throughout the assessment intervals. This finding complies with a previous study [16]. The refill problem was raised by patients as barrier to medications adherence, however; it was in contrast with a previous study [17]. In the latter study patients refill barrier was decreasing. A considerable number of patients find it difficult to read the label on their medications which may be attributed to high number of illiterate patients in the study population. A remarkable finding was the increasing number of patients reporting their dosage times were convenient. These findings dictated the importance of policies for refill, labeling and convenient dosing for improving adherence and to halt medications non-adherence.

Also there was no written policy for non-adherence risk reduction and for assessing any suspected medications non-adherence in all of the surveyed facilities. This might explain why even serious risks of non-adherence to medications were underreported. All these facts taken together would also indicated the decreased level of awareness about medications adherence safety concerns, which were recognized and implemented in most of the developed countries and some of the underdeveloped ones. Medications adherence is important in order to achieve better treatment outcomes in chronic diseases such as diabetes, hypertension and other cardiovascular diseases.

\subsection{Post Prandial Blood Glucose (PPBG) and HbA1c}

A clinical study by Avignon and co-workers showed that PPBG (post-lunch) is a better predictor of $\mathrm{HbA}_{1 \mathrm{c}}$ than FPG $>7.2 \mathrm{mmol} / \mathrm{L}$ before breakfast [18]. Postprandial hyperglycemia has been associated with increased risk of micro vascular [19] and macro vascular complications [20]. In this respect the results revealed a remarkable increase in the percentage of patients who have reached target PPBG levels from $28.0 \%$ at baseline to $49.3 \%$ after 6 months. Whether or not this has been associated with reduced microvascular or macrovascular complications deserve more attention in future studies in our population. Although the level of $\mathrm{HbA}_{1 \mathrm{c}}$ decreased; but the target was not reached $<7.0 \%$. This may be due to the fact that some patients failed to regularly monitor their $\mathrm{HbA}_{1 \mathrm{c}}$ which may have affected the final results.

\subsection{Mean Values of Blood Pressure (BP)}

The number of patients with controlled BP has increased from $50.0 \%$ to $89.0 \%$ within the study period. This was in agreement with previously published study [21]. The medications discontinuation rate in our population at the end of the final follow up was very low, $1.0 \%$. This may be attributed to the fact that patients were informed at each clinic visit to adhere to their medications and this was reinforced in each clinic visit. Furthermore, many patients has been switched to combinations therapy and ensured that it contains an ACE inhibitor. Our results lend support to the findings reported few years ago by [22].

\subsection{Results of Short Form Health Survey (SF-36)}

The largest improvements in HRQoL were for the physical functioning score and the emotional wellbeing scores (improved health). This finding was in concordance with that previously reported [23]. The provision of pharmacist education to patients with type 2 diabetes with or without cardiovascular diseases has resulted in improvement in terms of their HRQoL. The outcome of 
the pharmacist's interventions on patient's HRQoL demonstrated the relationship between this outcome measure and adherence to medications. Improvement in HRQoL may in part be attributed to the increased contact of these patients with the pharmacist, improved adherence to medications and resultant clinical improvement in patients' clinical outcomes. The current study lend support for the adoption of assessing HRQoL as an outcome for evaluating health education programs in patients with diabetes type 2 with or without cardiovascular diseases; who were on multiple medications.

\subsection{Impact of Education on Adherence}

Patient education on medication adherence is one of the main issues of interventions in the literature to enhance medication adherence [24]. In many of the surveyed facilities; health care providers appreciated the importance of education to patients in order to enhance the therapeutic success. The current study results demonstrated that a collaborative approach between the pharmacist and healthcare providers can facilitate implementing medications adherence concepts which were expected to contribute to improved patient outcomes. During the study period, patients were asked to visit their clinic regularly, in order to get controlled (target) blood glucose and BP levels. As patients adhered to see their physicians regularly they showed improvements in the therapeutic outcomes. However, patients have shown significant decrease in the BP and blood glucose levels. This was due to continued pharmacist's interventions and follow up. This was also in agreement with previously published study [25]. This finding dictates the importance of educating and training the patients about the different forms of medications adherence barriers. Non-adherence to long-term medications in chronic diseases is a worldwide problem. It has been estimated that $40.0 \%$ to $50.0 \%$ chronic disease patients are non-adherence to their prescribed treatment [26]. Non-adherence to medications is a major concern in the management of chronic disease such as hypertension $[27,28]$. The issue of the risk of medications non-adherence was not been identified in most of the surveyed PHCs facilities. However, most of the PHCs facilities in developed countries have implemented policies for medications adherence. In summary; this improved adherence to medications was associated with good control of blood glucose and BP, coupled with other positive effects observed in patient knowledge and reduction in difficulties in taking antihypertensive medications. The study highlighted that some patients lack knowledge about their medications, their respective disease type and its management as the main reasons for poor adherence. This finding was in concordance with recent published study [29]. This negative attitude places the pharmacist to play more vital role in responding to queries and in raising the awareness about medications adherence among patients and healthcare providers alike.

\subsection{Current Study Limitations}

There was a limitation with the current study, that medication adherence was measured using BMQ a screening behavioral measure, we anticipate that extent of adherence to medications may not be precisely estimated by this method.

\subsection{What Is New}

The pharmacist managed medications adherence, significantly improved patients' glycaemia control, blood pressure control and $\mathrm{HbA}_{1 \mathrm{c}}$. The findings of this study provide evidence of the effectiveness of pharmacists' educational and behavioral interventions in medication adherence.

\section{Conclusion}

There is a need for further research to highlight medications non-adherence and barriers to patients' adherence, in order to identify the type of interventions that may be needed for improving adherence and to evaluate whether improvements in awareness, knowledge and adherence are sustained in the longer term. We concluded that, the pharmacist's education and behavioural interventions were effective in increasing the medications knowledge and raising adherence issues in patients with type 2 diabetes with or without cardiovascular diseases.

\section{Acknowledgements}

The authors wish to thank all participating patients, physicians, pharmacists and nursing staff of primary health care facilities in Nyala, south Darfur state-Sudan; for their support. We applauded the contribution of: Dr. Mohammed Mandour [former General Director of Central Medical Supplies (CMS), Khartoum-Sudan], Professor AbuBakr Gurashi and Professor. El Hadi Mohammad (Dean Faculty of Pharmacy, University of Gezira).

\section{REFERENCES}

[1] M. Viswanathan, C. E. Golin, C. D. Jones, M. Ashok, S. J. Blalock, R. C. M. Wines, E. J. L. Coker-Schwimmer, D. L. Rosen, P. Sista and K. N. Lohr, "Interventions to Improve Adherence to Self-administered Medications for Chronic Diseases in the United States: A Systematic Review," Annals of Internal Medicine, Vol. 157, No. 11, 2012, pp. 785-795.

http://dx.doi.org/10.7326/0003-4819-157-11-201212040$\underline{00538}$ 
[2] S. Al-dabbagh, D. T. Mandh and S. Aswad, "Compliance of Hypertensive Patients to Management in Duhok Governorate Using Morisky-Green Test," Duhok Medical Journal, Vol. 4, No. 1, 2010.

[3] M. C. S. Wong, J. Y. Jiang and S. M. Griffiths, "Factors Associated with Antihypertensive Drug Compliance in 83884 Chinese Patients: A Cohort Study," Journal of Epidemiology and Community Health, Vol. 64, No. 10, 2010, pp. 895-890. http://dx.doi.org/10.1136/jech.2009.091603

[4] A. D. K. Bowry, W. H. Shrank, J. L. Lee, M. Stedman and N. K. Choudhry, "A Systematic Review of Adherence to Cardiovascular Medications in Resource-Limited Settings," Journal of General Internal Medicine, Vol. 26, No. 12, 2011, pp. 1479-1491. http://dx.doi.org/10.1007/s11606-011-1825-3

[5] A. G. Elzubier, A. A. Husain, I. A. Suleiman and Z. A. Hamid, "Drug Compliance among Hypertensive Patients in Kassala, Eastern Sudan," Eastern Mediterranean Health Journal, Vol. 6, 2000, pp. 100-105.

[6] A. Elnour, A. Shehab, A. Sadiq and N. H. Ellahham, "Monitoring the Doctors' Prescribing Patterns in Outpatient Polyclinic Setting: The Clinical Pharmacist's Approach," Khartoum Pharmacy Journal, Vol. 11, No. 1, 2008, pp. 6-11.

[7] B. L. Svarstad, B. A. Chewning, B. L. Sleath and C. Claesson, "The Brief Medication Questionnaire: A Tool for Screening Patient Adherence and Barriers to Adherence," Patient Education and Counseling, Vol. 37, No. 2, 1999, pp. 113-124. http://dx.doi.org/10.1016/S0738-3991(98)00107-4

[8] J. E. Brazier, R. Harper, N. M. Jones, A. O'Cathain, K. J. Thomas, T. Usherwood and L. Westlake, "Validating the SF36 Health Survey Questionnaire: New Outcome Measure for Primary Care," BMJ, Vol. 305, No. 6846, 1992 , pp. 160-164. http://dx.doi.org/10.1136/bmj.305.6846.160

[9] R. Adepu and S. S. M. ARri, "Influence of Structured Patient Education on Therapeutic Outcomes in Diabetes and Hypertensive Patients," Asian Journal of Pharmaceutical and Clinical Research, Vol. 3, No. 3, 2010.

[10] E. Vigneshwaran, Y. P. Reddy and N. Devanna, "Enhancing Quality of Life and Medication Adherence through Patient Education and Counseling among HIV/ AIDS Patients in Resource Limited Settings-Pre and Post Interventional Pilot Trial," British Journal of Pharmaceutical Research, Vol. 3, No. 3, 2013.

[11] M. Ho, C. L. Bryson and J. S. Rumsfeld, "Medication Adherence: It's Importance in Cardiovascular Outcomes," Journal of the American Heart Association, 2009.

[12] K. V. Nair, D. A. Belletti, J. J. Doyle, R. R. Allen, R. B. McQueen, J. J. Saseen, J. V. Griend, J. V. Patel, A. McQueen and S. Jan, "Understanding Barriers to Medication Adherence in the Hypertensive Population by Evaluating Responses to a Telephone Survey," Patient Preference and Adherence, Vol. 5, 2011, pp. 195-206.

[13] T. B. Hong, E. Z. Oddone, T. K. Dudley and H. B. Bosworth, "Medication Barriers and Anti-Hypertensive Medi- cation Adherence, the Moderating Role of Locus of Control," Psychology, Health \& Medicine, Vol. 11, No. 1, 2006, pp. 20-28.

http://dx.doi.org/10.1080/14786430500228580

[14] G. Harmon, J. Lefante and M. Wood-Krousel, "Overcoming Barriers: Role of Providers in Improving Patient Adherence to Antihypertensive Medications," Current Opinion in Cardiology, Vol. 21, No. 4, 2006, pp. 310315. http://dx.doi.org/10.1097/01.hco.0000231400.10104.e2

[15] S. B. Sridhar, M. G. Naraharib, K. C. Gurudevb and P. Gurumurthy, "Impact of Clinical Pharmacist-Provided Education on Medication Adherence Behaviour in ESRD Patients on Haemodialysis," IJPS, Vol. 5, No. 1, 2009, pp. 21-30.

[16] D. S. Friedman, S. R. Hahn, L. Gelb, J. Tan, S. N. Shah, E. E. Kim, T. J. Zimmerman and H. A. Quigley, "Doctor-Patient Communication, Health-Related Beliefs, and Adherence in Glaucoma Results from the Glaucoma Adherence and Persistency Study," Ophthalmology, Vol. 115 , No. 8, 2008, pp. 1320-1327. http://dx.doi.org/10.1016/j.ophtha.2007.11.023

[17] I. Krass, S. J. Taylor, C. Smith and C. L. Armour, "Impact on Medication Use and Adherence of Australian Pharmacists' Diabetes Care Services," Journal of the American Pharmacists Association, Vol. 45, No. 1, 2005, pp. 33-40. http://dx.doi.org/10.1331/1544345052843093

[18] A. Avignon, Radauceanu and L. Monnier, "Non-Fasting Plasma Glucose Is a Better Marker of Diabetic Control than Fasting Plasma Glucose in Type-II Diabetes," Diabetes Care, Vol. 20, 1997, pp. 1822-1826. http://dx.doi.org/10.2337/diacare.20.12.1822

[19] M. M. Engelgau, T. J. Thompson, W. H. Herman, J. P. Boyle, R. E. Aubert, S. J. Kenny, A. Badran, E. S. Sous and M. A. Ali, "Comparison of Fasting and 2-Hour Glucose and $\mathrm{HbA}_{1 \mathrm{c}}$ Levels Fordiagnosing Diabetes: Diagnostic Criteria and Performance Revisited," Diabetes Care, Vol. 20, No. 5, 1997, pp. 785-791. http://dx.doi.org/10.2337/diacare.20.5.785

[20] B. Balkau, M. Shipley, K. P. Jarrett, M. Pyorala, A. Forhan and E. Eschwege, "High Blood Glucose Concentration Is a Risk Factor for Mortality in Middle-Aged NonDiabetic Men: 20-Year Follow-Up in the Whitehall Study, the Paris Prospective Study and the Helsinki Policemen Study," Diabetes Care, Vol. 21, No. 3, 1998, pp. 360367. http://dx.doi.org/10.2337/diacare.21.3.360

[21] N. Fikri-Benbrahim, M. J. Faus, F. Martínez-Martínez, D. G. Alsina and D. Sabater-Hernández, "Effect of a Pharmacist Intervention in Spanish Community Pharmacies on Blood Pressure Control in Hypertensive Patients," American Journal of Health-System Pharmacy, Vol. 69, No. 15, 2012, pp. 1311-1318. http://dx.doi.org/10.2146/ajhp110616

[22] G. Corrao, A. Zambon, A. Parodi, E. Poluzzi, I. Baldi, L. Merlino, G. Cesana and G. Mancia, "Discontinuation of and Changes in Drug Therapy for Hypertension among Newly-Treated Patients: A Population-Based Study in Italy," Journal of Hypertension, Vol. 26, No. 4, 2008, pp. 819-824. 
http://dx.doi.org/10.1097/HJH.0b013e3282f4edd7

[23] M. Fujisawa, Y. Ichikawa, K. Yoshiya, S. Isotani, A. Higuchi, S. Nagano, S. Arakawa, G. Hamami, O. Matsumoto and S. Kamidono, "Assessment of Health-Related Quality of Life in Renal Transplant and Hemodialysis Patients Using the sf-36 Health Survey," Elsevier Science, 2000.

[24] L. Osterberg and T. Blaschke, "Adherence to Medication," New England Journal of Medicine, Vol. 353, No. 5, 2005, pp. 487-497.

http://dx.doi.org/10.1056/NEJMra050100

[25] J. P. Anaya, J. O. Rivera, K. Lawson, J. Garcia, J. Luna Jr and M. Ortiz, "Evaluation of Pharmacist-Managed Diabetes Mellitus under a Collaborative Drug Therapy Agreement," American Journal of Health-System Pharmacy, Vol. 65, No. 19, 2008, pp. 1841-1845. http://dx.doi.org/10.2146/ajhp070568

[26] J. Dunbar-Jacob, J. A. Erlen, E. A. Schlenk, C. M. Ryan, S. M. Sereika and W. M. Doswell, "Adherence in Chronic
Disease," Annual Review of Nursing Research, Vol. 18, No. 1, 2000, pp. 48-90.

[27] A. Lagi, A. Rossi, M. T. Passaleva, A. Cartei and S. Cencetti, "Compliance with Therapy in Hypertensive Patients," Internal and Emergency Medicine, Vol. 1, No. 3, 2006, pp. 204-208. http://dx.doi.org/10.1007/BF02934738

[28] J. J. Gascon, M. Sanchez-Ortuno, B. Llor, D. Skidmore and P. J. Saturno, "Why Hypertensive Patients Do Not Comply with the Treatment," Family Practice, Vol. 21, No. 2, 2004, pp. 125-130. http://dx.doi.org/10.1093/fampra/cmh202

[29] K. V. Mini, A. Ramesh, G. Parthasarathi, S. N. Mothi and V. T. Swamy, "Impact of Pharmacist Provided Education on Medication Adherence Behaviour in HIV/AIDS Patients Treated at a Non-Government Secondary Care Hospital in India," Journal of AIDS and HIV Research, Vol. 4, No. 4, 2012, pp. 94-99. 